\title{
Linkages Between Delayed Children's Social Interactions With Mothers and Peers
}

\author{
Michael J. Guralnick, Brian Neville, Mary A. Hammond, and Robert T. Connor \\ University of Washington
}

\begin{abstract}
The social dimensions of family-peer linkages of 4- to 6-year-old children $(N=63)$ with developmental delays (IQ range, 50-80) were examined in this study. Hierarchical regressions revealed consistent and meaningful patterns of association relating children's influence attempts directed toward their mothers and their interactions with peers. A similar association with peer interactions was found for children's ability to obtain compliance from their mothers. Evidence suggested the existence of a core behavioral pattern that children exhibit with different partners and in different contexts. The role of horizontal forms of parent-child interactions in promoting the peer relationships of children with delays was suggested, particularly in terms of an intervention approach for this group of children.
\end{abstract}

Contemporary analyses of young children's interpersonal development have revealed important linkages between the family and peer systems (Ladd \& Pettit, 2002). Parent-child interactions occurring in the numerous routines and activities of daily life constitute one critical relationship in which children's interpersonal skills and expectations regarding social relationships in general are formed; skills and expectations that may be highly relevant to children's social interactions with their peers. This family-peer linkage is particularly evident when children's social communication patterns are examined, as many aspects of children's social communications occurring in parent-child exchanges appear to have parallel forms when interacting with peers (e.g., Black \& Logan, 1995; Martinez, 1987; Putallaz, 1987).

However, the fact that parents and peers differ substantially along the dimensions of a partner's control and knowledge, among others, suggests the possibility that different interpersonal skills are required of children with each interactive partner. This raises questions as to the mechanisms through which well-documented family-peer linkages become established. In this connection, Russell, Pettit, and

\footnotetext{
This research was supported by a grant from the National Institute of Child Health and Human Development (RO1 HD37429). Support from Grant P30 HD02274 also facilitated our work. The authors wish to thank the many coders and other staff who participated in this project. Thanks are also due to the families for helping us to better understand factors influencing the peer relationships of young children with developmental delays.

Correspondence concerning this article should be addressed to Michael J. Guralnick, Center on Human Development and Disability, University of Washington, Seattle, WA 98195-7920. Electronic mail may be sent to mjgural@u.washington.edu.
}

Mize (1998) have pointed out that, despite the frequent occurrence of "vertical" or asymmetrical parent-child interactions in which substantial differences in control, knowledge, and other dimensions of the relationship are apparent, parents and children also engage frequently in "horizontal" or more symmetrical forms of interactions. In the context of horizontal parent-child interactions, parents orchestrate a more balanced and egalitarian series of exchanges with their child in which mutual influence is encouraged. Of significance, these horizontal or mutual patterns are also characteristic of interactions with peers (Hartup, 1996), thereby increasing the prospects for transfer of children's interaction patterns from the parent to the peer context. Accordingly, parent-child mutuality represented by the extent to which children attempt to influence their parents' behavior, such as by issuing requests or directives, and their ability to obtain compliance to those influence attempts may constitute an important link to the peer system (see Kochanska, 1992).

Studies of typically developing children examining associations between variations in parent-child interactions and variations in children's peer-related social competence have consistently supported this type of parent-peer linkage. For example, Putallaz (1987) observed that children's attempts to influence the behavior of their mothers, particularly through requests and weak directives, were positively associated with children's peer social status. Similarly, Black and Logan (1995) noted that the effectiveness of children's interaction patterns varied with the types of social communications the children used

(C) 2007 by the Society for Research in Child Development, Inc. All rights reserved. 0009-3920/2007/7802-0007 
(e.g., statements, directives, requests, relevance, interruptions), and that these patterns were similar when children interacted with parents and peers. Of special importance here was their finding that children who were rejected based on peer sociometric measures demonstrated less skill in their social communication exchanges and in gaining an appropriate response from their mothers to their requests and directives than accepted children.

Related work specifically examining children's interactions with peers has indicated that difficulties in social communication with respect to requests, directives, and obtaining responses or compliance are associated with children's low social status with peers (Black \& Hazen, 1990; Hazen \& Black, 1989). Similarly, children whose social communicative exchanges tend to be less relevant to ongoing play interactions with other children are those who are less successful in achieving their interpersonal goals and are judged to be of a lower social status with peers (e.g., Putallaz, 1983). In this connection, children's use of requests for information (i.e., questions) when interacting with parents may be an especially sensitive indicator of relevance that may carry over to the peer situation. Seeking information from another often occurs in the form of obtaining explanations that are generally linked to a consideration of the partner's ongoing activities. Moreover, like directives, which focus on altering a partner's behavior, requests also represent the child's interest in assuming an active role in social exchanges with their parents, thereby creating more mutual or horizontal forms of interaction.

Accordingly, one reason why higher levels of mutuality in parent-child interactions are associated with more socially competent play with peers and a higher peer social status may be due to more frequent opportunities available to children to observe, learn, and practice interpersonal skills in the parent-child context related to turn-taking, negotiation, compromise, and joint establishment of play (Lindsey, Mize, \& Pettit, 1997; Mize \& Pettit, 1997). This circumstance may generate generalized social knowledge regarding the use of influence strategies and the contextual and situational factors to consider when utilizing those strategies: knowledge that is clearly valuable when interacting with peers (Putallaz, 1987; Russell et al., 1998). Whatever factors may be responsible, and despite obvious differences in parent-child and child - child contexts (e.g., Mize, Pettit, \& Meece, 2000), the available evidence suggests that young typically developing children display important social communication patterns when interacting with their parents involving di- rectives (to alter a behavior) and requests (to seek information), as well as the ability to gain compliance to those directives and requests, that appear highly relevant to their interactions with peers. This relationship is particularly evident for typically developing children who have a low social status with their peers.

As a group, young children with developmental (cognitive) delays (IQs generally ranging from 50 to 80 based on standardized tests of intellectual development) also achieve a low social status with their peers as indicated by both peer sociometric and behavioral measures (Guralnick \& Groom, 1987b; Guralnick, 1999). To a large extent, the low social status of this group of children with delays can be attributed to the fact that, compared with appropriately matched groups, they exhibit unusual and pervasive peer interaction problems (Guralnick \& Groom, 1987a, 1987b; Guralnick, Connor, Hammond, Gottman, \& Kinnish, 1996; Kopp, Baker, \& Brown, 1992; Wilson, 1999). Most apparent are low levels of sustained interactive play, high levels of solitary play, and limited success in entering peer groups (see Guralnick, 1999). In addition, interactions with peers tend to create frequent conflicts, especially indicated by the strong correlations occurring between positive and negative interactions (Guralnick, Hammond, Connor, \& Neville, 2006). Of note, many of these difficulties appear to be associated with the use of certain social communication strategies. In particular, children with delays are less directive overall, appear to depend on more developmentally advanced companions to help organize play and make suggestions, are less responsive to peers, and have difficulties gaining appropriate responses to their influence attempts (Guralnick \& Groom, 1987a, 1987b; Guralnick \& Paul-Brown, 1989; Guralnick et al., 1996, 1998).

These problematic social communication patterns evident for peers have parallels in parent-child interactions. The available evidence suggests that children with delays have considerable difficulty in creating and sustaining mutual social exchanges during parent-child interactions, as these children tend to be less socially directive, present fewer social cues, and fail to be highly responsive (Spiker, Boyce, \& Boyce, 2002). As a consequence, parents of children with delays exhibit high levels of control as suggested by the use of directives (e.g., Landry, Garner, Pirie, \& Swank, 1994). In many respects, this is an appropriate response to their child's developmental level and social communication skills and one not incompatible with other positive relationship dimensions such as affection, warmth, and 
responsiveness (Crawley \& Spiker, 1983; Marfo, 1990; Roach, Barratt, Miller, \& Leavitt, 1998).

Although the literature for typically developing children linking variations in children's influence patterns during parent-child interactions to variations in the quality and quantity of peer interactions reviewed earlier is highly consistent, this important issue has not been investigated for children with developmental delays. Of note, contemporary conceptual frameworks suggest that similar developmental processes and mechanisms operate for typically developing children and children with developmental delays (Cicchetti \& Cohen, 1995; Guralnick, 2006; Hodapp, Burack, \& Zigler, 1998). Should such a similar pattern of family-peer linkages be obtained in this study, it would have important implications for intervention programs seeking to improve the peer relationships of young children with delays. In particular, it would provide an entirely new framework for developing specific strategies in the parent-child context involving child-initiated directives and requests to achieve a better balance between children's and parents' influence attempts. Prior interventions to promote the peer interactions of children with delays have relied almost exclusively on child-specific approaches in the peer context, achieving only minimal success (Guralnick, 2001).

Accordingly, in this study the hypothesis was examined that the social communication patterns of preschool-age children with developmental delays when interacting with their mothers would closely correspond to children's social interactions with their peers. Specifically, we expected that children's social communications consisting of measures of directives and requests to mothers (influence attempts), as well as mothers' compliance to children's requests and directives, would be associated with higher levels of success and involvement with peers. Mother-child interaction measures were derived from transcripts of videotaped records during both unstructured (free play) and structured (teaching task [TT]) situations, whereas peer interaction measures were obtained from analyses of videotapes of small playgroups involving unfamiliar peers. An initial peer group entry task was organized within the playgroups containing children unfamiliar to the children with delays to prompt for peer interactions related to relevance and initiations (see Putallaz \& Wasserman, 1990). Hierarchical regressions, first controlling for child characteristics, including chronological age, intellectual level, language, and behavior problems, were used to test the familypeer linkage hypothesis for three specific peer interaction measures: successful bids, initiations, and extent of solitary play. Children whose social bids to peers are more successful suggest more relevant social interactions, the frequency of initiations to peers indicates both an interest in others and a degree of assertiveness, and the extent of solitary play provides an index of children's overall level of participation with peers. In addition to testing these specific hypotheses, a composite peer measure was calculated to examine the family-peer correspondence with children's overall level of peer interactions.

\section{Method}

\section{Participants}

Young children with developmental delays were recruited through contact with local school districts in a large metropolitan community. Participating school districts distributed announcements describing an opportunity to participate in a larger research project intended to promote children's peer relationships. Information was sent to all parents whose children had an Individualized Education Program (IEP) and who attended an inclusive (mainstreamed) preschool or kindergarten. Parents who were interested in participating in the study contacted project staff directly, who then initiated a screening and identification process. To be included in this sample, a child had to meet the following criteria: (1) be between 48 and 78 months of age, (2) have a current IEP, (3) be experiencing difficulties in peer-related social competence as expressed by parent concerns in a structured phone interview, (4) have a primary female caregiver (minimum of a 6-month relationship, as mothers were our primary informants), and (5) obtain a Full Scale Intelligence Quotient (FSIQ) score between 50 and 80 on the Wechsler Preschool and Primary Scale of Intelligence-Revised (WPPSIR; Wechsler, 1989).

A number of exclusionary criteria were also established. Based on the Child Behavior Checklist (CBCL; Achenbach, 1991) completed by the mother (or other female caregiver) for each child, children who scored in the clinical range were excluded from the study to minimize disruptions in the peer playgroups described below (a $T$ score above 70 was established for children with developmental delays). A phone screening interview for mothers eliminated six children described as exhibiting major behavior problems. Two children were excluded because they obtained a $T$ score of 70 or above on the CBCL. 
Similarly, exclusion occurred if mothers scored at or above the 95th percentile on the Parent Domain of the Parenting Stress Index (Abidin, 1995). Three participants were excluded based on this criterion. Finally, children were excluded if English was not their primary language or if they had significant sensory or motor problems. No children were excluded on this basis. Over the course of a 7-year period, 63 children and families meeting our criteria were successfully recruited to participate. Table 1 contains the demographics of participating children and their families as well as other child characteristic measures.

\section{Child and Family Characteristic Measures}

Children were evaluated by psychologists with extensive prior experience working with young children with developmental delays. The following

Table 1

Child and Family Characteristics at Observations

\begin{tabular}{lcr}
\hline & M or $\%$ & $S D$ \\
\hline Child demographics & & \\
Age (months) & 63.52 & 7.65 \\
Gender (\% male) & 71.4 & \\
Ethnicity (\% Caucasian) $^{\mathrm{a}}$ & 73.0 & \\
Birth order (\% firstborn) $_{\text {Child measures }}$ & 33.3 & \\
Full Scale IQ $^{\mathrm{b}}$ & & \\
Adaptive behavior scales $^{\mathrm{c}}$ & 66.43 & 9.43 \\
TACL-R $^{\mathrm{d}}$ & 69.46 & 8.63 \\
EOWPVT-R $^{\mathrm{e}}$ & 68.38 & 15.73 \\
CBCL total behavior problems $^{\mathrm{f}}$ & 77.87 & 12.73 \\
Family demographics & 58.21 & 6.61 \\
Social status $^{\mathrm{g}}$ & & \\
Mother's age (years) $^{\text {Marital status (\% partnered) }}$ & 51.46 & 13.01 \\
Family income $^{\mathrm{h}}$ & 37.06 & 5.05 \\
Number other children in home & 92.1 & \\
\hline
\end{tabular}

Note. $\mathrm{SD}=$ standard deviation.

$N=63$.

${ }^{\text {a} B l a c k} 1.6 \%$, Hispanic, $4.8 \%$, Asian, $6.3 \%$, Native American, $1.6 \%$, Biracial, $12.7 \%$.

beschler Preschool and Primary Scale of Intelligence-Revised.

${ }^{c}$ Vineland Adaptive Behavior Scales, total standard score.

${ }^{\mathrm{d}}$ Test for Auditory Comprehension of Language-Revised, total score.

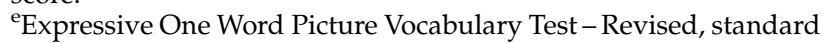
score.

${ }^{\mathrm{f}}$ Child Behavior Checklist, $T$ scores.

${ }^{\mathrm{g}}$ Hollingshead Four-Factor Index of Social Status; the mean score for this study represents medium business, minor professional, and technical jobs.

hincome scale: $1=<\$ 10,000,2=\$ 10,000-24,999, \quad 3=\$ 25,000-$ $39,999, \quad 4=\$ 40,000-59,999,5=\$ 60,000-79,999, \quad 6=\$ 80,000$ or more. child measures were included: (1) the WPPSI-R (Wechsler, 1989) was administered and used to obtain FSIQ scores; (2) the Vineland Adaptive Behavior Scales (Sparrow, Balla, \& Cicchetti, 1984) were administered to mothers with the total score used in this analysis; (3) the Test for Auditory Comprehension of Language-Revised (TACL-R; Carrow-Woolfolk, 1985) was administered and the total score was included in this analysis; (4) the Expressive One Word Picture Vocabulary Test-Revised (EOWPVT-R) (Gardner, 1990) was administered to children. The obtained raw score was converted to a standard score that was used for analysis; and (5) the CBCL (Achenbach, 1991) was administered to mothers who rated the frequency of different behavior problems from a 118 item questionnaire using a 3-point scale. Only the total score was used for analysis.

Standard demographic information about the family was also gathered via self-reports from mothers. Of note, 61 of 63 were the biological mothers of the children in the study. The Hollingshead Four Factor Index of Social Status (Hollingshead, 1975) was used to calculate a measure of family social status (range 8-66). Factors included in the calculation were level of education, marital status, gender, and occupation.

\section{Procedure}

Following the recruitment procedures outlined above, families whose children met all inclusionary criteria then received a packet of materials in the mail containing the various scales and questionnaires (including measures not part of the present study). All families contacted at this point continued to be interested in participating in this study. Mothers were then scheduled to bring their children to the laboratory for observations of both parent-child and child-child interactions for a period of 1 week. The mother-child sessions were conducted on Monday and Tuesday of that week, in which free play (20 min each) and TT (15 min each) sessions were scheduled each day. On Wednesday, Thursday, and Friday, children participated in playgroup sessions $(30 \mathrm{~min}$ of free play each) with unfamiliar peers (see descriptions of tasks and settings below). All data in this investigation were collected before children's participation in other phases of the larger study.

\section{Laboratory Observations of Mother-Child Interactions}

The focal child and mother were brought to the parent-child laboratory for mother-child free-play task (FPT) and TT observations. This laboratory 
contained three main experimental suites for videotaping and behavioral testing. Control rooms in each of the studios were equipped with two video cameras capable of pan-tilt and zoom plus four microphones. From the camera control station, the operator could preview the images using split-screen technology and make the necessary adjustments for the best view. A special effects generator was used to select which camera image was sent to the video cassette recorders. A time code character generator displayed time in minutes, seconds, and frame count, with additional fields to display number sequences for subject number and date.

For the FPT, the playroom in the laboratory was minimally furnished but contained a variety of toys, including those that could be used for pretend play (Sesame Street play set, stuffed animals, cars, dolls), and construction (blocks) as well as board games, coloring books, and puzzles. After entering the laboratory suite, the mother was informed that: "Now we'd like to watch him/her playing with you. Play however you would like for the next $20 \mathrm{~min}$. Feel free to use any of these toys, or if there are things you like to play that do not include these toys, you can do that as well. Just try to play as you normally would. I'll be back in $20 \mathrm{~min}$ with another activity for you." As noted, the interaction was videotaped with two cameras using split-screen technology from behind one-way mirrors. If bathroom breaks were needed, the timer was paused and resumed after the dyad returned. After $20 \mathrm{~min}$, the research assistant returned to the room and helped the mother and child return the toys to their places and prepare for the TT.

After a break, the mother and child were asked to build with Tinkertoys in the TT. The goal was to present the children with a challenge for which they would need help from their mothers so that her ability to organize and instruct could be observed. Tinkertoy building was selected for this observation because the task can vary from quite complex to quite simple depending on the abilities of the child and the level of support provided by the mother. Constructed models and picture models were presented and the child's task was to build one just like it. The Tinkertoys and the first model were placed on the floor and the child was given the following instructions: "Now I would like you to play with some Tinkertoys. First let's dump them on the floor. [The model is presented] This is a model of what I'd like you to make with them. I'd like you to make another one that looks just like this one." The mother was then given the following instructions: "Your job is to provide whatever help he/she needs to be able to build it. When he/she finishes with this one, I'll bring in another one." Children were presented first with a constructed model with a simple design (such as a swing set), which they used to build their own construction. Once this was completed, a second, more complicated constructed model was presented. If the child completed both of these in $<15 \mathrm{~min}$, the paper instructions from the Tinkertoy set were provided and the child was asked to select a model and build it. All children, regardless of their abilities, needed assistance with the task.

\section{Laboratory Observations of Child-Child Interactions}

Observations of focal children's play interactions with peers were carried out within a laboratory playroom in a different building designed to be similar to a typical preschool classroom. To record play interactions, the room was equipped with two video cameras operated by remote control, a radio telemetry microphone for the focal child, and an overhead microphone. A control panel with mixers balanced the auditory signals and allowed use of split-screen technology for video input. Child-child interactions were observed in playgroups (quartets) with unfamiliar, typically developing peers.

Typically developing children participating in the playgroups were recruited by distributing study announcements to local preschools, day-care centers, and schools. A brief telephone screen of interested parents was conducted during which the inclusion criteria for the children were described. Specifically, typically developing children needed to be between the ages of 48 and 78 months at the time of the playgroups (same as the focal children), have no known developmental, sensory, motor, or behavioral problems, and have English as a primary language. To assure that the children were typically developing, the TACL-R and the EOWPVT-R were administered to each child. To participate in the playgroups, children needed to obtain a standard score of at least 90 on each test. Children whose raw scores were greater than two standard deviations $(S D)$ above the mean based on the six-and-a-halfyear-old norms were excluded to eliminate excessive developmental differences between the typically developing children and the children with developmental delays. Mothers of typically developing children also completed the CBCL for their child. Those children who obtained $T$ scores above 66 were excluded from the sample. Typically developing children were assigned on an availability basis but matched for gender with the focal child. None of the typically developing children had any prior contact with the focal children. The average chronological 
age for the unfamiliar peers was 56.52 months $(S D=3.19)$. As was the case for the focal children, most peers were Caucasian (73.4\%). The ethnicity distribution for the peers was as follows: Black, 2.7\%; Hispanic, 0.5\%; Asian, 6.5\%; Native American, 0.5\%; and Biracial, $12.7 \%$.

\section{Playgroup Observations}

Based on this matching process (chronological age and gender), each of the focal children participated in three, 1-hr sessions with three typically developing peers in our laboratory playroom during each time period following the mother-child observations. Although all four children were unfamiliar with one another before the playgroups, the three typically developing children were introduced to one another and allowed to play together for $30 \mathrm{~min}$ 1 day before the first session. The purpose of this procedure was to further challenge the focal child by approximating a peer group entry task. The successive 1-hr periods allowed the focal child opportunities to become integrated within the group and permitted detailed observations of those interactions.

Playgroups were supervised by an experienced teacher in early childhood education. Children participated in a number of activities within each 1-hr session typical of young children's programs, including circle time, music, and snack. During the 30min free play period that was videotaped, the children had access to an extensive array of toys and equipment found in the playroom. Separate areas provided opportunities for housekeeping, blocks, puzzles, games, and manipulative toy play activities. During the free play period, teacher interactions were limited to providing assistance to ensure the children's safety.

\section{Mother-Child Interaction Coding Schemes}

Social communicative interactions and compliance patterns to requests and directives occurring between mothers and children were coded for each of the two FPT and TT sessions. Before coding could be carried out, all sessions were transcribed verbatim from the videotaped observations. Turns were first identified consisting of utterances produced in sequence by one participant, which continue until the participant signals that a response is expected, or is interrupted by the other participant (see Garvey, 1986; Sacks, Schegloff, \& Jefferson, 1978). If the participant pauses as if expecting a response (for $5 \mathrm{~s}$ ), and the other participant makes no verbal or nonverbal response, the next participant's utterance is considered the beginning of a new turn. "No response" is recorded for the intervening participant turn. Both verbal and nonverbal social communications were transcribed. A nonverbal utterance was defined as a distinct communicative act that may be an initiation of an activity (e.g., handing an object to the other participant) or a response to a request or directive (e.g., responding nonverbally to a question). The absence of a response to a request or directive is coded as a separate turn. Therefore, the coding scheme was based on a series of alternating turns between mother and child. Rules regarding the use of vocalizations, gestures, and other forms of communication (e.g., turn boundaries defined by the 5-s pause) were provided to transcribers.

Following the general system outlined by Black and Logan (1995), each utterance (verbal and nonverbal) in each turn was then coded in terms of its social communicative function as either a statement (conveying information about facts, activities, feelings, or interest), a request (posing a question), or a directive (seeking to obtain a behavioral response). Table 2 contains detailed definitions along with the subcategories that were coded for each of the three main social communication categories. Turns were typically relatively brief, but as many as nine social communications could be coded in any turn. These categories were mutually exclusive and exhaustive.

In addition to the three major social communication categories and their subcategories, the effectiveness of each influence attempt (i.e., request or directive) was determined. One of the following four compliance categories was coded for each request or directive issued by the child: (1) Comply-fully complies with request or directive. Correctness of the answer (to a request) or success of a response (to a directive) was not considered; (2) Deferral - the mother responds by deferring compliance to a later time, by making it contingent on the performance of some other action, or by defining a time within the session when a decision will occur. Relevant questions about a request or directive are also coded as a deferral; (3) Ignore-neither consent nor refusal is evident, with the mother not responding or acknowledging the request or directive; and (4) Refuse - mother makes a statement or physical action that is in opposition to the request or directive. A "no opportunity to comply" category was also available in the event that there was insufficient time to comply (e.g., mother carries out the action in the directive herself almost immediately).

Reliability. Reliability was first calculated for transcription of mother-child interactions. Two transcribers independently prepared transcripts for 
Table 2

Definitions for Main Social Communication Categories and Subcategories for Mother-Child Interactions

Statements: Conveying information about facts, activities, feelings, or interest. No direct obligation is placed on the other person to respond.

Explanation-description or narration of the ongoing play activity. Includes facts and other information about objects or events. Can occur in response to a previous turn or as a spontaneous statement. Example: "It's a Sesame Street toy"

Back-channel feedback - communicative signals that provide supportive feedback or simply indicate that one is listening. Example: "uh-huh," "hmm," or a head nod

Positive emotion-describes personal emotion or emotional expression that is positive (e.g., happiness, excitement) or makes positive evaluations referenced outside the current FPT or TT situation. Example: "I like doing this"

Negative emotion - describes personal emotion or emotional expression that is negative (e.g., anger, sadness). Includes negative evaluations referenced outside the current FPT or TT. Example: "I'm angry"

Positive feedback - a statement indicating that the other person's actions or statements are correct. Example: “Yes, that's the way to do it"

Corrective feedback - a statement indicating that the other person's actions or statements are incorrect. Example: “No, that doesn't go there"

Praise - an individual makes a positive evaluation of the qualities, skills, abilities, or behavior of the other person in the setting. Example: "You're good at this"

Criticism - an individual makes a negative evaluation of the qualities, skills, abilities, or behavior of the other person in the setting. Example: "I don't like it when you scream"

Requests: Posing a question to another person, thereby placing an obligation to respond. The intent is to obtain a statement from the other person.

Request explanation - soliciting statements of explanation (see above) from the other person. Included are requests for descriptions of an ongoing activity, an explanation about how to do something in the free-play or teaching activity, information about what the other is doing, or clarification of a previous utterance. Example: "What is this?"

Request feedback — soliciting feedback about the quality of one's performance from the other person. Example: "Is this right?"

Request emotion - soliciting a statement of feelings from the other person. Example: "Are you angry?"

Request personal evaluation — soliciting a statement of personal evaluation (praise or criticism) from the other person. Example: "Am I good at this?"

Directives: Seeking to obtain a behavioral response from the other person. An obligation to respond with action is placed on the other person.

Suggestion - proposing a specific activity or offering an object to another person intended to produce a behavioral response but done in a manner that allows the person a choice regarding participation. Example: "You could put the block here"

Imperative - directing another person to perform some action with no power to decline implied by the utterance. "Pick up the blue one" Mitigated imperative - mitigating an imperative by use of "please" or "okay?" or similar forms presented at the beginning or end of the utterance. Example: "Please pick up the blue one"

Restriction - demanding that the other person stop an activity. Example: "Don't do that"

$20 \%$ of the FPT and TT sessions. Interrater reliability, in terms of percentage agreement, was calculated for words, punctuation, and turn boundaries. Agreement was high in all instances: $87 \%$ for words (range $77-95 \%$ ); $87 \%$ for punctuation (range $80-96 \%$ ); and $86 \%$ for turns (range $72-95 \%$ ).

For the social communication and compliance codes, coders were initially trained using precoded reliability tapes. Pilot tapes were then coded until coders achieved Cohen's $\kappa$ of .70 or greater with an experienced coder. Training averaged approximately 2 months and was carried out separately for the social communication and compliance codes. Interrater reliability was then obtained on $20 \%$ of the FPT and TT sessions. Cohen's $\kappa$ was computed between the head coder and each of the other coders for the social communication codes for the full matrix (including subcategories) and for the compliance categories based on a series of 15-min segments. For the FPT, coders obtained a mean $\kappa$ of .75 for social communication and .66 for compliance. For the TT, coders obtained a mean $\kappa$ of .74 for social communication and .66 for compliance. Review of these 15-min segments provided additional opportunities for discussion of intercoder differences. For each of the main social communication and compliance codes that were used in the analysis, intraclass correlation coefficients were calculated. Correlations were uniformly high, ranging from .72 to $.99(M=.90)$.

\section{Child-Peer Play Coding Schemes}

Only the play interactions of the focal child were coded. The 30-min playgroup observations were 
coded using two well-established schemes: (a) the Play Observation Scale (POS) and (b) the Individual Social Behavior Scale (ISBS).

For the revised version of the POS (Rubin, 2001), coders recorded the quality of social participation and levels of cognitive play during each 10-s interval. This scale consists of 10 mutually exclusive and exhaustive social participation categories with the cognitive play measures (e.g., dramatic play) nested within the main social participation categories of solitary, parallel, and group play (see Rubin, 2001, for detailed definitions of the measures). Variations of this scale have been applied effectively to children with disabilities similar to those in this study for playgroups (e.g., Guralnick et al., 1996). Evidence with respect to convergent and discriminant validity suggests that the scale of social participation constitutes a useful index of a more general construct of peer competence (Provost \& LaFreniere, 1991).

Videotapes from both time periods were sent to the University of Maryland where highly trained staff coded all sessions. Training for POS coding was extensive and initially took place utilizing playgroup tapes from a separate study. For prestudy reliability for the full variable matrix, including cognitive play categories nested within the social participation categories, all raters reached the minimum criterion and obtained an overall Cohen's $\kappa$ of .77. After training was completed, interrater reliability on approximately $20 \%$ of randomly selected playgroup sessions was calculated between pairs of coders and produced an overall $\kappa$ of .70. Intercoder differences were resolved through review and discussion.

Each videotape was reviewed a second time by our research group to examine specific peer-related social behaviors of the focal child. For this purpose, the ISBS, based on the work of White and Watts (1973) and adapted in a manner similar to Doyle, Connolly, and Rivest (1980) and to Guralnick and Groom (1985, 1987a, 1987b), was used. A version of this scale has been applied successfully to preschoolage children with delays and to typically developing children as they interacted in playgroups similar to those described in this study (Guralnick et al., 1996).

Observers recorded continuously the occurrence of individual social behaviors defined by 25 categories. Categories were designed to record the social interactions of the focal child as directed to peers (e.g., seeks attention, leads peer, expresses hostility) as well as to record the social behaviors of the focal child in response to directed activities of peers (e.g., follows lead of peer). Through the application of this scale, the frequencies of both positive and negative social behaviors could be identified both directed to and in response to peers. In addition, where appropriate, each of the focal child individual social behaviors was classified as to whether it was an initiation. A focal child-initiated event is one in which no prior verbal or nonverbal interaction occurred for at least three seconds. Nine of the 25 categories were also judged as either successful or unsuccessful, with definitions specific to each social behavior category. The ISBS coding manual with detailed definitions and coding rules can be obtained by contacting the first author.

Coders were free to review any segment of the tape as often as needed. The coding protocol was divided into 30-s intervals following the time codes superimposed on the tape. Although coding was continuous, these divisions provided a structure for the coding task and served as a framework for establishing reliability within the event-based system. Coders were considered to be in agreement if codes matched within a specified 10-s interval using the "best-fit" matching method (Hollenbeck, 1978). A reliability manual describing this method is available from the first author. In addition to the 25 ISBS categories, a "no interaction" event was included to complete the possible options within each 30-s interval.

Before coding, four coders were trained for a period of 10-12 weeks on the ISBS. Videotapes of pilot or related playgroups were used for training and final pretesting of reliability assessments. For prestudy reliability, calculated in this manner, all coders achieved the minimum average criterion of agreement for individual social behaviors necessary for participation of $75 \%$ (overall $\kappa=.70$ ) on two consecutive 30 -min tapes. The mean reliabilities for playgroup observations carried out during the course of the study on $20 \%$ of the total were as follows: individual social behaviors, $\kappa=.75$ (range $=.62-.80$ ), $M$ percentage agreement $=84 \%$ (range $=76-91 \%$ ), agreement on successful/unsuccessful, $M=93 \%$ (range $=85-100 \%)$, and agreement on initiations, $M=88 \%$ (range $=57-100 \%$ ). To minimize observer drift, weekly coding meetings were held and interobserver disagreements were resolved by discussion and reviewing tapes.

\section{Representative Measures of Peer-Related Social Interactions}

Ten measures were selected from the POS and ISBS codes to provide a broad representation of children's peer-related social interactions (see Guralnick et al., 1996). Measures selected from the POS were: solitary play (playing alone), parallel play 
(playing next to another child), group play (playing with another child), and peer conversation (talking, questioning but not playing). Measures selected from the ISBS were the frequencies of successful social bids and initiations, as well as the composite measures of positive directed to peer (leads peer positive - direct and indirect, uses peer as resource, joins peer, seeks peer's attention, seeks peer's agreement; $\alpha=.81$ ), negative directed to peer (leads peer negative-direct and indirect, expresses hostility, takes unoffered object; $\alpha=.73$ ), responsive to peer positive (follows peer's social bids to gain attention, to lead positively - direct or indirect, to use as a resource, and to seek agreement; $\alpha=.82$ ), and nonresponsive to peer positive (fails to follow peer's social bids for the same categories in prior measure; $\alpha=.69$ ). Intraclass correlation coefficients were calculated for each of these 10 measures to index interrater reliability and were high in all instances, $M=.95$ (range $.80-.99$ ).

Descriptive data (SDs are in parentheses) for the 10 peer interaction measures (rate per minute) are as follows: ISBS successful bids, .42 (.43); ISBS initiations, .21 (.17); ISBS positive directed to peer, .63 (.66); ISBS negative directed to peer, $.20(.21)$; ISBS responsive to peer positive, $.27(.24)$; ISBS nonresponsive to peer positive, .20 (.16); and POS solitary play, 2.81 (1.34); POS parallel play, 0.87 (0.56); POS group play, 0.31 (0.47); POS peer conversation, 0.39 (0.38). As discussed earlier, an Overall Peer Interaction composite and measures of initiations, success of social bids, and extent of solitary play were selected as dependent measures for a series of hierarchical multiple regressions to test hypotheses regarding the associations between the child-child measures and children's influence attempts (requests and directives) and their ability to achieve compliance during mother-child interactions.

\section{Results}

Descriptive Information and Comparisons Between Tasks

Table 3 presents descriptive data (frequencies and proportions) for the social communication and compliance measures for children for both the FPT and TT summed across the two sessions. Scores were transformed if needed to normalize the distributions, but untransformed scores are presented in the tables. The mean number of turns for children was 255.22 $(S D=48.06)$ for the FPT and $261.48(S D=53.43)$ for the TT. As noted earlier, the coding scheme was designed to yield essentially the same number of turns

Table 3

Social Communication and Compliance Measures for Free Play and Teaching Tasks

\begin{tabular}{|c|c|c|c|c|c|c|c|}
\hline & \multirow{2}{*}{\multicolumn{2}{|c|}{$\begin{array}{c}\text { Free-play } \\
\text { task }\end{array}$}} & \multirow{2}{*}{\multicolumn{2}{|c|}{ Teaching task }} & \multicolumn{3}{|c|}{ Comparisons between tasks } \\
\hline & & & & & \multicolumn{2}{|c|}{ Mean differences } & \multirow[b]{2}{*}{ Pearson correlations } \\
\hline & $M$ & $S D$ & $M$ & $S D$ & $t$ tests $(d f=61)$ & Effect size $d$ & \\
\hline \multicolumn{8}{|l|}{ Frequency measures } \\
\hline \multicolumn{8}{|l|}{ Mother } \\
\hline Compliance $^{1}$ & 1.02 & 0.55 & 0.97 & 0.69 & 0.62 & 0.11 & $.47^{* * *}$ \\
\hline \multicolumn{8}{|l|}{ Child } \\
\hline Total communications & 7.69 & 2.07 & 8.22 & 2.89 & -1.85 & 0.33 & $.65^{* * *}$ \\
\hline Total statements & 5.72 & 1.58 & 6.39 & 2.30 & $-2.63^{*}$ & 0.47 & $.54^{* * *}$ \\
\hline Total requests & 0.82 & 0.53 & 1.22 & 0.91 & $-4.50^{* * *}$ & 0.81 & $.67^{* * *}$ \\
\hline Total directives & 1.15 & 0.76 & 0.61 & 0.50 & $6.81^{* * *}$ & 1.22 & $.52^{* * *}$ \\
\hline \multicolumn{8}{|l|}{ Proportion measures } \\
\hline \multicolumn{8}{|l|}{ Mother } \\
\hline Compliance-proportion $^{\mathrm{a}}$ & 0.60 & 0.13 & 0.60 & 0.18 & 0.12 & 0.02 & .09 \\
\hline \multicolumn{8}{|l|}{ Child } \\
\hline Total statements-proportion & 0.75 & 0.09 & 0.79 & 0.09 & $-2.92^{* *}$ & 0.52 & $.49^{* * *}$ \\
\hline Total requests-proportion & 0.11 & 0.06 & 0.14 & 0.08 & $-3.94^{* * *}$ & 0.71 & $.57^{* * *}$ \\
\hline Total directives-proportion & 0.14 & 0.08 & 0.08 & 0.05 & $7.73^{* * *}$ & 1.39 & $.46^{* * *}$ \\
\hline
\end{tabular}

Note. $M=$ mean; $S D=$ standard deviation.

Free-Play Task $N=63$; Teaching Task $N=62$. Frequency measures are rate per minute. All measures are summed over the two time periods for each task.

${ }^{a}$ Frequency and proportion measures for the full compliance subcategory.

${ }^{*} p<.05, * * p<.01, * * * p<.001$. 
for each member of the dyad. Only the main social communication categories for children are presented in Table 3 (statements, requests, and directives), along with mothers' compliance to children's directives or requests. With respect to the subcategories, the explanation subcategory dominated the main statement category (proportions: .90 FPT, .93 TT), the request for explanation subcategory was the most prevalent for the main request category (proportions: $.88 \mathrm{FPT}, .86 \mathrm{TT}$ ), and imperatives occurred most often for directives (proportions: .61 FPT, .67 TT), although suggestions occurred frequently as well (proportions: .27 FPT, .24 TT). The compliance measures in Table 3 consisted of the frequency or proportion of the full compliance subcategory (four subcategories).

Comparisons between the two tasks were carried out for each of the measures in Table 3. A series of $t$ tests (see Table 3) revealed that child social communications were significantly higher in the TT than the FPT for both the frequency and proportion of statements and requests. In contrast, directives, both frequency and proportion, were higher in the FPT than the TT. No differences were obtained for the frequency or proportion measures of mother compliance $(p>.05)$. As also seen in Table 3 , despite the differing demands of the two tasks, children were highly consistent in their social communication and compliance patterns as all measures were significantly correlated. Although mother compliance frequency was significantly correlated across tasks, mother compliance proportion was not.

\section{Correspondence Between Child Social Communications With Mother and Their Peer Interactions}

To evaluate the linkages between children's social communications with mothers and children's interactions with peers, a series of hierarchical multiple regressions were carried out. To control for child characteristics, child's chronological age, FSIQ, TACL-R, EOWPVT-R, and CBCL Total Behavior Problems scores were entered in Step 1. As our primary interest was in children's attempts to influence their mothers, the frequencies of both requests and directives were chosen to be entered into Step 2 of the analysis. Proportion and frequency measures were highly interrelated for both the FPT (directives, $r=.92, p<.001$; requests, $r=.91, p<.001)$ and the TT (directives, $r=.88, p<.001$; requests, $r=.90, p<.001$ ).

Four regressions were carried out examining the associations with the three child-child measures hypothesized to correspond closely to patterns of child-to-mother influence attempts. As noted, these dependent measures consisted of the frequencies of successful bids, initiations, and solitary play. In addition, to assess the correspondence between children's influence attempts and general peer participation, an overall peer interaction composite was included as a fourth dependent variable based on the 10 measures selected for the ISBS and POS noted earlier. A principal components analysis revealed that a single factor accounted for $61 \%$ of the variance. All measures loaded positively except for solitary play. Although positive interactions predominated, the fact that positive and negative interactions were positively correlated is consistent with the conflictprone nature of the social interactions of children with delays discussed earlier. The Overall Peer Interaction composite measure was computed by converting each component measure to a scaled score ranging from 0 to 100 and averaging the 10 scaled measures (POS solitary play was reversed).

The results of the four regressions for the FPT are presented in Table 4. As can be seen, child characteristics entered at Step 1 did not account for significant variance for any of the four dependent measures, and none of the $\beta$ weights were significant for any of the five child characteristic measures $(p>.05)$. In contrast, children's attempts to influence mothers' behavior in the form of the frequency of directives and attempts to obtain information in the form of requests significantly predicted all four measures of peer interaction. Except in two instances (initiations and solitary play), both requests and directives made independent contributions to the association. The most variance accounted for was obtained for the successful bids measure $\left(\Delta R^{2}=.27\right.$ after controlling for child characteristics).

These regressions were repeated for the TT and produced a similar although less consistent pattern (see Table 5). Once again, child characteristics failed to account for significant variance. Children's influence attempts to mothers, however, significantly predicted three of the four measures (with the exception of solitary play), but the overall proportion of variance accounted for after controlling for child characteristics was generally lower for this task (maximum $\Delta R^{2}=.20$ for initiations).

Taken together, children who adopted more active roles in altering their mothers' behavior (as indexed by directives) or communicated in a manner more likely to achieve connected discourse when interacting with their mothers (as indexed by requests) also demonstrated higher levels of social interactions with peers. These relationships were obtained for three key measures of peer interaction including the ability to successfully achieve responses to their social bids from peers, to be active in the form of 
Table 4

Hierarchical Multiple Regression Analyses Predicting the Four Peer Interaction Variables for the Free-Play Task

\begin{tabular}{|c|c|c|c|c|}
\hline Variables & $\Delta R^{2}$ & $d f$ & $\Delta F$ & $\beta$ \\
\hline \multicolumn{5}{|l|}{ Successful bids } \\
\hline Step 1 & .06 & 5,57 & 0.71 & \\
\hline Child characteristics & & & & $n s^{\mathrm{a}}$ \\
\hline Step 2 & .27 & 2,55 & $10.79^{* * *}$ & \\
\hline Requests & & & & $.29^{*}$ \\
\hline Directives & & & & $.37^{* *}$ \\
\hline \multicolumn{5}{|l|}{ Initiations } \\
\hline Step 1 & .08 & 5,57 & 0.95 & \\
\hline Child characteristics & & & & $n s^{\mathrm{a}}$ \\
\hline Step 2 & .19 & 2,55 & $7.21^{* *}$ & \\
\hline Requests & & & & $.33^{* *}$ \\
\hline Directives & & & & .23 \\
\hline \multicolumn{5}{|l|}{ Solitary play } \\
\hline Step 1 & .11 & 5,57 & 1.43 & \\
\hline Child characteristics & & & & $n s^{\mathrm{a}}$ \\
\hline Step 2 & .18 & 2,55 & $6.77^{* *}$ & \\
\hline Requests & & & & $-.36^{* *}$ \\
\hline Directives & & & & -.15 \\
\hline \multicolumn{5}{|l|}{ Peer interaction composite } \\
\hline Step 1 & .06 & 5,57 & 0.76 & \\
\hline Child characteristics & & & & $n s^{\mathrm{a}}$ \\
\hline Step 2 & .25 & 2,55 & $9.86^{* * *}$ & \\
\hline Requests & & & & $.38^{* *}$ \\
\hline Directives & & & & $.26^{*}$ \\
\hline
\end{tabular}

Note. $d f=$ degree of freedom; $n s=$ not significant; $R=$ variance.

${ }^{a}$ None of the child characteristic measures (chronological age, full scale IQ [FSIQ], Test for Auditory Comprehension of LanguageRevised [TACL-R], Expressive One Word Picture Vocabulary Test-Revised [EOWPVT-R], and Child Behavior Checklist [CBCL] Total Behavior Problems) were significant for any of the four dependent variables.

${ }^{*} p<.05, * * p<.01, * * * p<.001$.

initiating to peers, and to not become isolated from their peers (solitary play). An overall measure of peer interaction (composite) produced a similar pattern of relationships. As noted, these associations were independent of children's age, cognitive and language levels, and extent of behavior problems.

\section{Relationship Between Mothers' Compliance Patterns and Children's Peer Interactions}

Children's ability to achieve compliance from their mothers to their requests and directives and its relationship with peer interaction patterns was examined next. The frequency of mothers' compliance to their children's requests and directives served as an index of the mutuality of the motherchild relationship, representing some combination of the mother's willingness to comply and the child's
Table 5

Hierarchical Multiple Regression Analyses Predicting the Four Peer Interaction Variables for the Teaching Task

\begin{tabular}{|c|c|c|c|c|}
\hline Variables & $\Delta R^{2}$ & $d f$ & $\Delta F$ & $\beta$ \\
\hline \multicolumn{5}{|l|}{ Successful bids } \\
\hline Step 1 & .06 & 5,56 & 0.68 & \\
\hline Child characteristics & & & & $n s^{\mathrm{a}}$ \\
\hline Step 2 & .15 & 2,54 & $5.20^{* *}$ & \\
\hline Requests & & & & $.26^{*}$ \\
\hline Directives & & & & $.26^{*}$ \\
\hline \multicolumn{5}{|l|}{ Initiations } \\
\hline Step 1 & .08 & 5,56 & 1.01 & \\
\hline Child characteristics & & & & $n s^{\mathrm{a}}$ \\
\hline Step 2 & .20 & 2,54 & $7.30^{* *}$ & \\
\hline Requests & & & & .13 \\
\hline Directives & & & & $.30^{*}$ \\
\hline \multicolumn{5}{|l|}{ Solitary play } \\
\hline Step 1 & .12 & 5,56 & 1.54 & \\
\hline Child characteristics & & & & $n s^{\mathrm{a}}$ \\
\hline Step 2 & .08 & 2,54 & 2.82 & \\
\hline Requests & & & & $-.30^{*}$ \\
\hline Directives & & & & .02 \\
\hline \multicolumn{5}{|l|}{ Peer interaction composite } \\
\hline Step 1 & .06 & 5,56 & 0.75 & \\
\hline Child characteristics & & & & $n s^{\mathrm{a}}$ \\
\hline Step 2 & .16 & 2,54 & $5.49^{* *}$ & \\
\hline Requests & & & & $.35^{* *}$ \\
\hline Directives & & & & .15 \\
\hline
\end{tabular}

Note. $d f=$ degree of freedom; $n s=$ not significant; $R=$ variance.

${ }^{a}$ None of the child characteristic measures (chronological age, full scale IQ [FSIQ], Test for Auditory Comprehension of Language Revised [TACL-R], Expressive One Word Picture Vocabulary Test-Revised [EOWPVT-R], and Child Behavior Checklist [CBCL] Total Behavior Problems) were significant for any of the four dependent variables.

${ }^{*} p<.05, * * p<.01, * * * p<.001$.

ability to express comprehensible and appropriate requests or directives. As hypothesized, this degree of mutuality, indexed by the mother compliance measure, should be positively associated with the peer interaction measures.

Hierarchical multiple regressions were then carried out separately for the FPT and TT for each of the four peer interaction-dependent measures, again entering child characteristics at Step 1 with mothers' frequency of compliance entered at Step 2. For both tasks, the results revealed a pattern similar to that obtained for children's influence attempts. Again, child characteristics failed to reach significance for any measure or task $(p>.05)$. For the FPT, significant effects for mother compliance were obtained for all four dependent measures: successful bids, $\Delta R^{2}=.31$, $p<.001, \beta=.57$; initiations, $\Delta R^{2}=.20, p<.001, \beta=.41$; solitary play, $\Delta R^{2}=.18, \quad p<.001, \quad \beta=-.43 ;$ and 
Overall Peer Interaction composite, $\Delta R^{2}=.23, p<.001$, $\beta=.48$. Corresponding results for the TT were as follows: successful bids, $\Delta R^{2}=.15 ; p<.01, \beta=.40$; initiations, $\Delta R^{2}=.16, p<.01, \beta=.40$; solitary play, $\Delta R^{2}=.09, p<.05, \beta=-.29$; and Overall Peer Interaction composite, $\Delta R^{2}=.16, p<.01, \beta=.41$.

This association with the frequency of mother compliance is potentially important as it suggests that greater levels of mutuality in mother-child interactions are associated with higher levels of interactions with peers. However, this relationship was also clearly related to children's overall influence attempts. Specifically, when the regressions were recalculated entering the frequencies of child requests and directives to mothers in Step 2, the frequency of mother compliance (in Step 3) accounted for significant variance only for successful bids in the FPT $\left(\Delta R^{2}=.05, p<.05, \beta=.57\right)$. In this connection, the frequency and proportion measures of mother compliance were significantly correlated $(r=.43$, $p<.01$ for the FPT and $r=.41, p<.01$ for the TT). Consequently, higher rates of compliance achieved on an absolute basis were associated with children experiencing a higher likelihood that their efforts to influence their mothers would result in compliance.

\section{Discussion}

In this study, we examined important dimensions of family-peer linkages for young children with developmental delays. The results revealed that children's influence attempts as indexed by the use of directives and requests when interacting with their mothers corresponded in meaningful ways to their peer-related social interactions. Specifically, across both free play and TTs, children's attempts to influence their mothers were associated with greater effectiveness in gaining a response to their social bids from peers, higher levels of assertiveness in the peer context as indexed by the frequency of initiations, and less isolation in the peer group as indexed by solitary play. This relationship was also apparent for an overall measure of peer interactions. Moreover, a similar pattern was obtained for the frequency of mothers' compliance to children's influence attempts. Of importance, our findings were not related to relevant child characteristics, as children's chronological age, intelligence, language, and behavior were controlled in the analyses. Accordingly, these results suggest that children with developmental delays display core patterns of social behavior that are expressed in two entirely different social contexts. As is the case for typically developing children, assertiveness (directives) and relevance-seeking (re- quests) efforts of children with developmental delays in the parent-child context are highly relevant to those social communication skills needed to be effective in the peer context (Black \& Logan, 1995; Putallaz, 1987; Russell et al., 1998). As discussed below, these findings substantially advance our understanding of the peer relationships of children with developmental delays and suggest new approaches for interventions designed to address the unusual peer interaction problems evident for this group of children.

From an intervention perspective, it is important to place the level of peer interactions of children with developmental delays in perspective. Although there is considerable individual variation, as noted earlier these children exhibit substantial difficulties in establishing relationships with peers. Indeed, as a group, the overall level of peer interactions and their social status with peers is quite low and all forms of child-child social interactions develop at an unusually slow pace (e.g., Guralnick et al., 2006). Interventions designed to promote the peer interactions of young children with developmental delays have focused almost exclusively on altering the behavior of children in the peer context. Unfortunately, these efforts have achieved only limited success (Guralnick, 1999). Our results suggest an entirely new direction for intervention to address these substantial peer interaction difficulties, that is, promoting more mutual and horizontal relationships between mothers and children. More specifically, interventions designed to encourage the social communication influence attempts of children with developmental delays that promote assertive styles of interacting and enhance the likelihood of relevant discourse by encouraging requests for information during parentchild interactions may be of particular value, as any benefits may extend to other partners and contexts (Lindsey et al., 1997; Mize \& Pettit, 1997). Successful efforts here will also increase the likelihood of mother compliance to those influence attempts.

Interventions intended to foster attempts to initiate social interactions and to enhance informationseeking behavior to promote relevance, in particular, are not easily accomplished in peer contexts, especially when young children are involved. However, initial structuring of appropriate activities and interactions can be more readily achieved in the parent-child context. The use of scripts, for example, to encourage requests and other information-seeking activities to promote relevance and initiative taking can be effective (Nelson, 1981). This is especially the case if these activities are organized within typical family routines (Fiese, Wilder, \& Bickham, 2000), 
which, in turn, can promote the types of generalized social knowledge likely to be essential in any interpersonal context (Lindsey et al., 1997). Moreover, techniques such as these can be readily incorporated into comprehensive (both child and family focused) peer interaction intervention programs to test this hypothesis (Guralnick, Connor, Neville, \& Hammond, 2006), and constitutes an important new direction for future research.

From a theoretical perspective, the fact that the core pattern of associations evident for typically developing children also appears to hold for children with developmental delays strongly suggests that it is reasonable to expect that the many other familypeer linkages that have been found for typically developing children will also apply to children with delays. Moreover, it is likely that similar mechanisms and processes are responsible for the patterns obtained in this study. Future work using longitudinal designs testing specific models of influence will be needed to evaluate this hypothesis. At minimum, our findings further support the contribution of developmental models integrating the science of normative development, risk, and disability in relation to family influences on early development (Cicchetti \& Cohen, 1995; Guralnick, 2006).

Previous research has found weak or no relationships between children's cognitive and language levels and the peer relationships of young children with developmental delays similar to those in this sample (e.g., Guralnick \& Groom, 1987b). As indicated in the regressions, none of the cognitive or language measures were significantly associated with any peer interaction measure for the range of children included in this study. It is the case that certain aspects of cognition (e.g., verbal ability) or language (e.g., receptive language) do exhibit modest associations with peer interactions and that the association between child cognitive and language levels and peer interactions becomes more apparent overtime (Guralnick \& Groom, 1985; Guralnick et al. 2006). An association between children's behavior problems and peer interactions has, however, been a consistent finding (Guralnick \& Groom, 1985; Guralnick et al., 1996), and the exclusion of children in the current sample with high levels of behavior problems likely affected this relationship. Nevertheless, it should be noted that although approximately $25 \%$ of children with delays can be expected to reach the standard clinical cutoff for behavior problems (Baker, Blacher, Crnic, \& Edelbrock, 2002), our criterion for excluding children from this study was substantially less stringent $(T$ score $=70)$, thereby minimizing this concern.
Other issues should also be considered in interpreting the generality of these findings. Specifically, we did not conduct analyses to examine gender differences due to the insufficient number of girls in our sample, although such differences are to be expected (see Rose \& Rudolph, 2006; Rubin, Coplan, Chenm, Buskirk, \& Wojslawowicz, 2005; Underwood, 2004). As in our study, boys are typically disproportionately represented in samples of children with delays (e.g., Gallimore, Keogh, \& Bernheimer, 1999). Our sample was also quite homogenous, consisting mainly of Caucasian families whose primary language was English. Clearly, additional work involving more heterogeneous samples is needed to determine the generalizability of our findings. Moreover, the peer context consisted only of initially unfamiliar peers in an unfamiliar setting, and it is possible that different results might be found if the social challenge was not so demanding. As noted, the peer entry task was included as it depends so strongly on children producing relevant social communications including information seeking (Putallaz \& Wasserman, 1990). Finally, the exclusion not only of children with major behavior problems but also mothers with unusually high levels of maternal stress may certainly have produced a more favorable parent-child pattern of interactions (e.g., Girolametto \& Tannock, 1994). Similarly, the fact that children were enrolled in inclusive programs suggests parental interest in their child's social relationships. Given the relatively high proportion of intact families with adequate income levels, sufficient time and other resources to devote to supporting their child's social relationships were available. However, it is important to note that peer interaction difficulties are characteristic of the vast majority of children with delays, and mothers in this sample noted that such problems were apparent for their child.

In summary, important linkages were obtained in this first study examining the association between children's social communications and compliance patterns with mothers and their interactions with peers for children with developmental delays. Evidence suggested the existence of core behavioral patterns that children exhibit with different partners and in different contexts. Although the origins of these family-peer linkages could not be established in this study, the findings were consistent with research and theory based on typically developing children, suggesting the role of mutual or horizontal forms of parent-child relationships as a means of promoting social communication skills relevant to children's peer interactions. The application of knowledge of familypeer linkages for typically developing children, especially their mechanisms of influence, combined with a 
knowledge of the unique concerns for children with delays, provide important directions for future peercompetence research, particularly intervention research, for this group of young children.

\section{References}

Abidin, R. R. (1995). Parenting Stress Index (3rd ed.). Odessa, FL: Psychological Assessment Resources Inc.

Achenbach, T. M. (1991). Manual for the Child Behavior Checklist/4-18 and 1991 profile. Burlington: Department of Psychiatry, University of Vermont.

Baker, B. L., Blacher, J., Crnic, K. A., \& Edelbrock, C. (2002). Behavior problems and parenting stress in families of three-year old children with and without developmental delays. American Journal on Mental Retardation, 107, 433444.

Black, B., \& Hazen, N. L. (1990). Social status and patterns of communication in acquainted and unacquainted preschool children. Developmental Psychology, 26, 379-387.

Black, B., \& Logan, A. (1995). Links between communication patterns in mother - child, father - child, and child peer interactions and children's social status. Child Development, 66, 255-271.

Carrow-Woolfolk, E. (1985). Manual for the test for auditory comprehension of language-revised. Allen, TX: DLM Teaching Resources.

Cicchetti, D., \& Cohen, D. J. (1995). Perspectives on developmental psychopathology. In D. Cicchetti \& D. J. Cohen (Eds.), Developmental psychopathology: Vol. 1. Theories and methods (pp. 3-20). New York: Wiley.

Crawley, S. B., \& Spiker, D. (1983). Mother-child interactions involving two-year-olds with Down syndrome: A look at individual differences. Child Development, 54, $1312-1323$.

Doyle, A., Connolly, J., \& Rivest, L. (1980). The effect of playmate familiarity on the social interactions of young children. Child Development, 51, 217-223.

Fiese, B. H., Wilder, J., \& Bickham, N. L. (2000). The family context in developmental psychopathology. In A. J. Sameroff, M. Lewis, \& S. M. Miller (Eds.), Handbook of developmental psychopathology (2nd ed., pp. 115-136). New York: Kluwer Academic/Plenum Publishers.

Gallimore, R., Keogh, B. K., \& Bernheimer, L. P. (1999). The nature and long-term implications of early developmental delays: A summary of evidence from two longitudinal studies. In L. M. Glidden (Vol. Ed.), International review of research in mental retardation (Vol. 22, pp. 105-135). San Diego, CA: Academic Press.

Gardner, M. F. (1990). Expressive one word picture vocabulary test-revised. Novato, CA: Academic Therapy Publications.

Garvey, C. (1986). Peer relations and the growth of communication. In E. C. Mueller \& C. R. Cooper (Eds.), Process and outcome in peer relationships (pp. 329-345). San Diego, CA: Academic Press.

Girolametto, L., \& Tannock, R. (1994). Correlates of directiveness in the interactions of fathers and mothers of children with developmental delays. Journal of Speech and Hearing Research, 37, 1178-1192.

Guralnick, M. J. (1999). Family and child influences on the peer-related social competence of young children with developmental delays. Mental Retardation and Developmental Disabilities Research Reviews, 5, 21-29.

Guralnick, M. J. (2001). Social competence with peers and early childhood inclusion: Need for alternative approaches. In M. J. Guralnick (Ed.), Early childhood inclusion: Focus on change (pp. 481-502). Baltimore: Brookes.

Guralnick, M. J. (2006). Family influences on early development: Integrating the science of normative development, risk and disability, and intervention. In $\mathrm{K}$. McCartney \& D. Phillips (Eds.), Blackwell handbook of early childhood development (pp. 44-61). Oxford, UK: Blackwell Publishing.

Guralnick, M. J., Connor, R., Hammond, M., Gottman, J. M., \& Kinnish, K. (1996). Immediate effects of mainstreamed settings on the social interactions and social integration of preschool children. American Journal on Mental Retardation, 100, 359-377.

Guralnick, M. J., Connor, R. T., Neville, B., \& Hammond, M. A. (2006). Promoting the peer-related social development of young children with mild developmental delays: Effectiveness of a comprehensive intervention. American Journal on Mental Retardation, 111, 336-356.

Guralnick, M. J., \& Groom, J. M. (1985). Correlates of peer related social competence in developmentally delayed preschool children. American Journal of Mental Deficiency, 90, $140-150$.

Guralnick, M. J., \& Groom, J. M. (1987a). Dyadic peer interactions of mildly delayed and nonhandicapped preschool children. American Journal of Mental Deficiency, 92, 178-193.

Guralnick, M. J., \& Groom, J. M. (1987b). The peer relations of mildly delayed and nonhandicapped preschool children in mainstreamed playgroups. Child Development, 58, 1556-1572.

Guralnick, M. J., Hammond, M. A., Connor, R. T., \& Neville, B. (2006). Stability, change, and correlates of the peer relationships of young children with mild developmental delays. Child Development, 77, 312-324.

Guralnick, M. J., \& Paul-Brown, D. (1989). Peer-related communicative competence of preschool children: Developmental and adaptive characteristics. Journal of Speech and Hearing Research, 32, 930-943.

Guralnick, M. J., Paul-Brown, D., Groom, J. M., Booth, C. L., Hammond, M. A., Tupper, D. B., et al. (1998). Conflict resolution patterns of preschool children with and without developmental delays in heterogeneous playgroups. Early Education and Development, 9, 49-77.

Hartup, W. W. (1996). The company they keep: Friendships and their developmental significance. Child Development, $67,1-13$.

Hazen, N. L., \& Black, B. (1989). Preschool peer communication skills: The role of social status and interaction context. Child Development, 60, 867-876. 
Hodapp, R. M., Burack, J. A., \& Zigler, E. (1998). Developmental approaches to mental retardation: A short introduction. In J. A. Burack, R. M. Hodapp, \& E. Zigler (Eds.), Handbook of mental retardation and development (pp. 3-19). New York: Cambridge University Press.

Hollenbeck, A. R. (1978). Problems of reliability in observational research. In G. P. Sackett (Ed.), Observing behavior: Vol. 2. Data collection and analysis methods (pp. 7998). Baltimore: University Park Press.

Hollingshead, A. B. (1975). Four factor index of social status. Unpublished manuscript. Department of Sociology, Yale University, New Haven.

Kochanska, G. (1992). Children's interpersonal influence with mothers and peers. Developmental Psychology, 28, $491-499$.

Kopp, C. B., Baker, B. I., \& Brown, K. W. (1992). Social skills and their correlates: Preschoolers with developmental delays. American Journal on Mental Retardation, 96, 357366.

Ladd, G. W., \& Pettit, C. H. (2002). Parenting and the development of children's peer relationships. In M. H. Bornstein (Ed.), Handbook of parenting: Vol. 5. Practical issues in parenting (2nd ed., pp. 269-304). Mahwah, NJ: Lawrence Erlbaum.

Landry, S. H., Garner, P. W., Pirie, D., \& Swank, P. R. (1994). Effects of social context and mothers' requesting strategies on Down's syndrome children's social responsiveness. Developmental Psychology, 30, 293-302.

Lindsey, E. W., Mize, J., \& Pettit, G. S. (1997). Mutuality in parent-child play: Consequences for children's peer competence. Journal of Social and Personal Relationships, 14, 523-538.

Marfo, K. (1990). Maternal directiveness in interactions with mentally handicapped children: An analytical commentary. Journal of Child Psychology and Psychiatry, $31,531-549$.

Martinez, M. A. (1987). Dialogues among children and between children and their mothers. Child Development, 58, 1035-1043.

Mize, J., \& Pettit, G. S. (1997). Mothers' social coaching, mother-child relationship style, and children's peer competence: Is the medium the message? Child Development, 68, 312-332.

Mize, J., Pettit, G. S., \& Meece, D. W. (2000). Explaining the link between parenting behavior and children's peer competence: A critical examination of the "mediating process" hypothesis. In K. Kerns, J. Contreras, \& A. M. Neal-Barnett (Eds.), Family and peers: Linking two social worlds (pp. 137-168). New York, NY: Greenwood/Praeger.

Nelson, K. (1981). Social cognition in a script framework. In J. H. Flavel \& L. Ross (Eds.), Social cognitive development: Frontiers and possible futures (pp. 335-364). Hillsdale, NJ: Lawrence Erlbaum.

Provost, M. A., \& Lafreniere, P. J. (1991). Social participation and peer competence in preschool children: Evi- dence for discriminate and convergent validity. Child Study Journal, 21, 57-72.

Putallaz, M. (1983). Predicting children's sociometric status from their behavior. Child Development, 54, 1417-1426.

Putallaz, M. (1987). Maternal behavior and children's sociometric status. Child Development, 58, 324-340.

Putallaz, M., \& Wasserman, A. (1990). Children's entry behavior. In S. R. Asher \& J. D. Coie (Eds.), Peer rejection in childhood (pp. 60-89). Cambridge, UK: Cambridge University Press.

Roach, M. A., Barratt, M. S., Miller, M. J., \& Leavitt, L. A. (1998). The structure of mother-child play: Young children with Down syndrome and typically developing children. Developmental Psychology, 34, 77-87.

Rose, A. J., \& Rudolph, K. D. (2006). A review of sex differences in peer relationship processes: Potential tradeoffs for the emotional and behavioral development of girls and boys. Psychological Bulletin, 132, 98-131.

Rubin, K. H. (2001). The Play Observation Scale. The Center for Children, Relationships and Culture, University of Maryland, College Park: Author.

Rubin, K. H., Coplan, R. J., Chen, X., Buskirk, A. A., \& Wojslawowicz, J. C. (2005). Peer relationships in childhood. In M. H. Bornstein \& M. E. Lamb (Eds.), Developmental psychology: An advanced textbook (5th ed., pp. 469 -512). Mahwah, NJ: Lawrence Erlbaum.

Russell, A., Pettit, G. S., \& Mize, J. (1998). Horizontal qualities in parent-child relationships: Parallels with and possible consequences for children's peer relationships. Developmental Review, 18, 313-352.

Sacks, H., Schegloff, E. A., \& Jefferson, G. (1978). A simplest systematics for the organization of turn-taking of conversation. In J. Schenkein (Ed.), Studies in the organization of conversational interaction (pp. 7-57). New York: Academic Press.

Sparrow, S. S., Balla, D. A., \& Cicchetti, D. V. (1984). Vineland adaptive behavior scales. Circle Pines, MN: American Guidance Service.

Spiker, D., Boyce, G. C., \& Boyce, L. K. (2002). Parent-child interactions when young children have disabilities. In L. M. Glidden (Ed.), International review of research in mental retardation (Vol. 25, pp. 35-70). San Diego, CA: Academic Press.

Underwood, M. K. (2004). Gender and peer relations: Are the two gender cultures really all that different? In J. B. Kupersmidt \& K. A. Dodge (Eds.), Children's peer relations : From development to intervention (pp. 21-36). Washington, DC: APA Publications.

Wechsler, D. (1989). Wechsler preschool and primary scale of intelligence - revised. San Antonio, TX: The Psychological Corporation.

White, B. L., \& Watts, J. C. (1973). Experience and environment (Vol. 1). Englewood Cliffs, NJ: Prentice-Hall.

Wilson, B. (1999). Entry behavior and emotion regulation abilities of developmentally delayed boys. Developmental Psychology, 35, 214-222. 